\title{
메트포민의 최신지견
}

\section{홍상모}

한양대학교 의과대학 한양대학교구리병원 내과

\section{Recent Perspective of Metformin}

\section{Sangmo Hong}

Department of Internal Medicine, Hanyang University Guri Hospital, Hanyang University College of Medicine, Guri, Korea

\begin{abstract}
Metformin has been used clinically more than 60 years in type 2 diabetes as the first-line drug for treatment. Metformin has been prescribed in more than $80 \%$ of Korean patients with diabetes. Despite long-term use and wide prescription of metformin in patients with type 2 diabetes, many questions remain. Recent advances have revealed a new mechanism of action and new benefits of metformin. In this article, we review recent advances regarding metformin treatment.
\end{abstract}

Keywords: Cardiovascular diseases; Delayed-action preparations; Diabetes mellitus, type 2; Metformin

$$
\text { 서론 }
$$

메트포민은 중세 시대부터 다뇨와 빈뇨를 동반한 당뇨병 환자의 치료에 사용되던 프렌치 라일락의 활성 성분인 구아니 딘(guanidine)에서 유래하였다[1]. 프렌치 라일락은 임상적으 로 사용하기에는 독성이 있었기 때문에 이를 해결하기 위해서
1929년 Slotta와 Tschesche가 여러 바이구아나이드 약제를 보고한 이후, 1957년 유럽에서 메트포민이 승인되면서 이후 2 형당뇨병 환자에서 치료제로 공식적으로 사용되기 시작하였 다[1]. 이후 60년 이상의 임상경험과 여러 연구결과를 통해서 대한당뇨병학회 당뇨병 진료지침뿐만 아니라 미국당뇨병학 회, 유럽당뇨병학회 및 세계당뇨병연맹을 포함한 여러 기관의

Corresponding author: Sangmo Hong

Division of Endocrinology and Metabolism, Department of Internal Medicine, Hanyang University Guri Hospital, Hanyang University College of Medicine, 153 Gyeongchun-ro, Guri 11923, Korea, E-mail: lanugo35dagmail.com

Received: Apr. 28, 2021; Accepted: May 2, 2021

This is an Open Access article distributed under the terms of the Creative Commons Attribution Non-Commercial License (http://creativecommons.org/licenses/by$\mathrm{nc} / 4.0 /$ ) which permits unrestricted non-commercial use, distribution, and reproduction in any medium, provided the original work is properly cited.

Copyright (C) 2021 Korean Diabetes Association 
당뇨병 진료지침에서는 생활습관 개선만으로 목표치에 도달 하지 못한 경우 첫 치료약제로 메트포민을 권고하였다[2]. 이 들 가이드라인은 메트포민을 1차 치료약제로 권고한 근거로 다른 당뇨병약물 사용에서 관찰되는 저혈당과 체중증가의 위험 없이 혈당을 개선하고 심혈관 사망률을 감소시키며 약 제 비용이 저렴하다고 제시하였다[3]. 메트포민의 심혈관질환 예방효과는 1998년 발표된 The UK Prospective Diabetes Study (UKPDS) 34 연구결과가 대표적이다[4]. 이 연구에서 비만을 동반한 2형당뇨병 신환 1,704명을 대상으로 약물치 료 없는 대조군 $(\mathrm{n}=951)$ 과 메트포민군 $(\mathrm{n}=342)$, 설포닐유 레아/인슐린군 $(\mathrm{n}=411)$ 으로 나누어 당뇨병 신환에서 어떠한 치료적 접근이 더 우월한지를 비교하였다. 연구결과에 따르면 메트포민군이 대조군 대비 당뇨병 관련 이벤트 발생을 32\% 감소시켰으며 당뇨병 관련 사망을 $42 \%$, 전체 사망을 $36 \%$ 줄였고 심근경색증 발생을 39\% 줄였다. 또한 설포닐유레아 나 인슐린으로 치료한 환자군에 비해 당뇨병 관련 이벤트 발 생 $(P=0.003)$ 및 전체 사망 $(P=0.02)$, 뇌경색 $(P=0.03)$ 발 생이 적었다. 하지만 메트포민은 UKPDS 임상을 제외하고는 이후 심혈관질환 예방효과와 관련해 비교 임상자료가 적으 며 최근 시행된 심혈관계 결과 연구(Cardiovascular Outcome Trial, CVOT)를 통해 유익한 효과가 입증된 GLP-1수용체작 용제나 SGLT2억제제에 비해서는 그 근거 수준이 낮다. 이번 글에서는 최근 발표된 메트포민 관련 연구를 살펴보도록 하 겠다[4].

$$
\text { 메트 포민의 작용 기전 }
$$

2015년 대한당뇨병학회에서 발표된 당뇨병 Fact Sheet를 살펴보면 우리나라 당뇨병 환자 중 $80 \%$ 이상이 메트포민을 복용하고 있다. 광범위한 메트포민 사용에도 불구하고 메트 포민의 정확한 작용 메커니즘에 대해서는 아직도 연구가 진행 중에 있다. 1995년 메트포민은 간 포도당신생성을 $75 \%$ 까지 감소시켜 혈당을 감소시키는 것으로 보고되었다[5]. 이후 연 구에서 이는 $\mathrm{AMPK}$ 의 활성화를 통해 혈당 감소가 이루어지 는 것으로 확인되었다. 하지만 최근 메트포민의 작용 메커니
즘에 대한 연구는 위장관에서의 작용에 초점을 맞추고 있다. 전임상 및 임상연구에서 메트포민은 (1) 장내 포도당 흡수 및 이용을 증가시키고 (2) 담즙산 흡수를 억제하고 (3) 위장 미 생물을 변경하고 (4) 인크레틴 호르몬인 GLP-1의 분비를 증 가시킨다고 알려져 있다. 최근에는 이를 종합하여 메트포민은 담즙산 흡수를 감소시켜 담즙산과 원위장 내 수용체의 상호 작용을 강화하여 GLP-1 분비를 증가시켜 혈당을 감소시킨 다는 모델이 제시되고 있다[6].

$$
\text { 메트포민의 제형에 따른 효과 차이 }
$$

메트포민 제형은 속방형(immediate-release), 서방형 (extended-release), 지연형(delayed release)의 3가지가 있 다. 속방형 메트포민은 초기 형태의 메트포민으로 경구 투여 하면 약 40\%의 용량이 상부 소장(십이지장 및 근위 공장)에 서 흡수되고 약 $10 \%$ 만이 회장과 결장에서 흡수되어 생체 이 용률은 약 $50 \%$ 로 알려져 있다[7]. 다른 제형에 비해서 위장관 증상이 심하고 하루 2회에서 3회 복용해야 하는 단점이 있 다. 반면에 서방형은 장에서 천천히 흡수되어서 속방형과 생 체 이용률이 비슷하나 하루에 1 번 복용하면 되고 위장관 증 상이 적은 것이 특징이다[8]. 최대 혈장 메트포민 농도는 기존 의 속방형 제형과 비교하여 서방형 제형이 더 느리게 도달하 지만, 둘 다 총 일일 복용량에 비례하여 유사한 전신노출량 을 가진다. 위장관을 통해 흡수된 메트포민은 간문맥을 통해 직접 간으로 공급되고, 유기양이온수송체-1 (organic cation transporters-1, OCT-1)을 통해 혈장 농도보다 약 10배 높 은 농도로 간세포에 축적되며 남은 메트포민은 다른 혈장 단백질과 결합되지 않은 채 순환하다 신장을 통해 배설된다 [9]. 이는 메트포민의 혈당조절작용이 간에서의 포도당신생성 을 억제하여 발휘된다는 현재의 개념과 일치한다. 또한 흡수 되지 않은 메트포민은 장의 점막에 축적되고(혈장보다 300 배 더 높은 농도로) 궁극적으로 대변에서 제거된다[10]. 하지 만 최근 들어 메트포민의 작용 기전에 위장관 흡수를 통한 간의 포도당신생성 억제뿐만 아니라 회장의 $\mathrm{L}-$ 세포에 작용 하여 혈당을 낮추는 기전도 중요하다는 근거가 증가함에 따 
라 지연형 메트포민이 개발되었다. 지연형 메트포민(Elcelyx Therapeutics; NewMet, San Diego, CA, USA)은 장용 코 팅기술을 사용하여 주로 원위 소장에서 메트포민을 방출하 도록 디자인되어 있어 소장을 통한 흡수를 줄이고 보다 많 은 양의 메트포민이 회장의 $\mathrm{L}-$ 세포에서 작용하도록 디자인되 어 있다[11]. 최근 발표된 지연형 메트포민 1상 약동학 연구에 따르면 $1,000 \mathrm{mg}$ 지연형 메트포민의 생체 이용률은 같은 용 량의 속방형과 서방형의 약 50\%였으나 GLP-1 (1.6 1.9배)과 peptide YY (1.4 1.5배)의 혈중 농도는 지연형이 서방형에 비 해 높았다. 12주, 2상, 다기관, 위약 대조, 용량 범위 연구에 서는 240명의 2형당뇨병 피험자들을 무작위 배정하여 지연형 메트포민 $600 \mathrm{mg}, 800 \mathrm{mg}$ 또는 1,000 mg을 매일 1회 투여 하였고 대조군으로 맹검 위약 또는 비맹검 서방형 메트포민 $1,000 \mathrm{mg}$ 또는 2,000 mg을 투여하였다[12]. 모든 용량의 지 연형 메트포민은 위약에 비해 12 주 동안 공복혈당 수치가 통 계적으로 유의하게 개선되었고 서방형 메트포민에 비해 효능 이 약 40\% 증가했다[12]. 또한 위장관 증상과 연관된 부작용 은 서방형 메트포민에 비해서 차이가 없었다. 지연형 메트포민 은 매우 흥미로운 약으로 그 낮은 흡수율로 신기능이 떨어 진 환자에서도 상대적으로 안전하게 사용할 수 있을 것으로 기대되고 있다[13]. 하지만 향후 지연형 메트포민에 대한 다양 한 추가 연구가 필요할 것으로 생각된다.

\section{심혈관계 안정성}

심혈관사망률 감소를 입증한 연구는 앞서 제시한 UKPDS 34 연구결과가 대표적이다[4]. 하지만 이 연구는 비만한 당뇨 병 환자를 대상으로 한 제한된 결과이고 스타틴과 안지오텐 신전환효소억제제(ACE 억제제) 등의 약제의 사용 이전에 연 구된 결과로 지금의 임상 환경에 적용하기에는 제한이 따른 다. 따라서 이후 여러 연구에서 메트포민의 심혈관질환에 대 한 효과에 대해서 추가 연구가 진행되었는데 대표적으로 인 슐린 치료 중인 당뇨병 환자에서 메트포민의 효과를 평가한 HOME (Hyperinsulinemia: the Outcome of Its Metabolic Effects) 연구가 있다[14]. 이 연구결과에 따르면 메트포민은
위약 대비 체중증가를 예방하고, 혈당을 개선하고, 인슐린 요 구량을 줄이며, 대혈관합병증 발생을 39\% ( $P=0.02)$ 감소 시켰으나 미세혈관합병증 발생에는 영향이 없었다[14]. 메트포 민과 설포닐유레아계 약제인 글리피자이드의 장기적인 심혈관 질환 발생에 대한 영항을 비교한 연구도 있었다[15]. 이 연구의 대상자는 이미 관상동맥질환을 동반한 304 명의 환자를 대상 으로 진행되었는데 글리피자이드 환자군 대비 메트포민 치료 군에서 5년간 평균 당화혈색소의 차이는 없었으나 주요 심혈 관질환의 발생이 $46 \%$ (hazard ratio [HR] 0.54, $P=0.0026$ ) 감소하였다는 보고가 있었다[15]. 최근 발표된 관상동맥질환 을 가진 당뇨병 환자(40개 연구, 1,066,408명)를 대상으로 메 트포민의 심혈관질환에 대한 효과를 분석한 메타분석 연구 에 따르면 메트포민이 심혈관계 사망(-19\%), 모든 원인 사망 (-33\%)과 심혈관질환(-17\%)을 줄인다고 보고하였다[16]. 물 론 모든 당뇨병 환자를 대상으로 분석한 메타분석에서도 메 트포민의 심혈관질환 예방 효과에 대해서 입증한 연구결과가 있지만[17] 메트포민의 심혈관질환에서의 효과는 주로 진행된 당뇨병 환자, 비만한 당뇨병 환자, 심혈관질환을 동반한 당 뇨병 환자 등 주로 심혈관질환의 고위험군에서 입증이 되어 있다. 이는 메트포민의 심혈관 예방효과가 특정 환자군에서만 효과가 있는 것인지 아니면 메트포민의 심혈관질환 예방효과 가 기대보다 크지 않아서 그러한 것인지에 대해서는 추가 연 구가 필요할 것으로 생각된다.

\section{메트포민과 심부전}

당뇨병은 심혈관질환의 위험이 높다고 알려져 있지만 이와 별도로 심부전 위험도 높다고 알려져 있다. 특히 최근 당뇨병 환자의 치료가 발전하고 기대수명이 늘어나면서 당뇨병 환자 에서의 심부전 유병률은 지속적으로 증가하고 있다. 또한 최 근 SGLT2억제제의 심부전에 대한 효과가 알려지면서 당뇨병 환자에서의 심부전에 대한 관심이 증가하고 있다. 그 결과로 최근 메트포민의 심부전에 대한 효과를 알아본 연구결과들이 발표되고 있다. 당뇨병은 없지만 인슐린저항성 또는 당뇨병전 단계의 관상동맥질환을 가진 환자에서 메트포민 $(2,000 \mathrm{mg})$ 
투여가 위약 대비 좌심실비대에 어떠한 영향을 주는지 12개월 간 추적한 연구가 있었다[18]. 이 연구결과에 따르면 메트포민 의 투여는 확장기말 좌심실 질량을 체표면적으로 나누어 보 정한 좌심실 비후 지수(left ventricular mass index, LVMI $\left[\mathrm{g} / \mathrm{m}^{1.7}\right]$ )를 개선하였고(absolute mean difference $-1.37,95 \%$ confidence interval [CI] -2.63 to $-0.12, P=0.033$ ) 이는 체 중과 혈압변화 등 여러 연관 변수에 독립적이었다고 보고하 였다[18]. 최근 발표된 후향적 코호트연구에서는 당뇨병 환 자에서 메트포민의 복용이 심부전으로 인한 입원의 위험( $\mathrm{HR}$ $0.571,95 \%$ CI 0.526 0.620) [19]을 줄였다고 보고하였고 다 른 연구에서는 신부전을 동반한 당뇨병 환자에서 메트포민의 복용이 설포닐유레아에 비해서 심부전으로 인한 입원의 위험 (HR 0.79, 95\% CI 0.67 0.93) [20]을 줄였다고 보고하였다. 향후 메트포민과 심부전에 관한 전향적 연구가 필요할 것으 로 생각된다.

\section{메트포민과 심혈관계 결과 연구(CVOT)}

지난 십여 년간 GLP-1수용체작용제나 SGLT2억제제로 진 행된 여러 CVOT 연구에서 심혈관질환과 심부전, 신장 합병증 에 대한 효과가 입증되면서 1차 당뇨병 약제로서의 메트포민 의 지위가 흔들리고 있다. 최근 유럽에서는 심혈관질환이 매 우 높은 경우 당뇨병 환자에서 1차 약제로 메트포민보다 먼 저 GLP-1수용체작용제나 SGLT2억제제를 사용할 것을 권 고하였다[21]. 하지만 이러한 CVOT 연구 참여자의 $70 \%$ 이 상이 메트포민도 복용하고 있었다는 점을 간과하면 안 된다. 최근 이러한 문제로 CVOT 연구의 메트포민 사용 유무에 따 른 post-hoc 연구결과들이 발표되고 있다. 이러한 post-hoc 연구결과들은 CVOT 연구결과에서 메트포민의 역할을 엿볼 수 있어서 흥미롭다. 2017년 Diabetes Care에 DPP-4억제제 로 진행된 3개의 CVOT 연구(TECOS, EXAMINE, SAVORTIMI)를 메타분석한 결과가 발표되었다[22]. 이 연구결과에 따르면 메트포민을 기저에 복용하고 있었던 환자에서 $\mathrm{DPP}-4$ 억제제를 추가하는 것이 메트포민을 기저에 복용하지 않고 $\mathrm{DPP}-4$ 억제제를 추가하는 것보다 심혈관질환의 위험이 보
다 낮음을 확인할 수 있었다 $(P=0.036)$ [22]. 2020년에는 EMPA-REG OUTCOME 연구 post-hoc 분석 결과가 발표 되었는데 연구자들은 엠파글리플로진(empagliflozin)의 좋 은 효과가 메트포민의 동반 투여와 관계없이 심혈관질환과 사망에서 나타났으나 신장질환 진행에서는 메트포민을 사용 하지 않는 환자에게 엠파글리플로진의 이점이 더 클 수 있다 고 보고하였다[23]. 하지만 이는 메트포민이 이미 기저 보호 효과를 주어서 엠파글리플로진 효과를 약화되어 보이게 한 것일 수 있다. 실제로 이 논문에서 신장질환 진행의 발병률은 엠파글리플로진과 메트포민을 모두 복용하지 않은 환자에 서 가장 높았고(109.0/100 patient-years [pt-yrs]), 메트포 민만 복용(66.5/100 pt-yrs), 엠파글리플로진(52.7/100 pt$\mathrm{yrs})$, 두 약제 모두 복용(46.1/100 pt-yrs) 순이었다. 반면 에 DECLARE-TIMI 58 post-hoc 분석 결과에서는 다파글 리플로진(dapagliflozin) 효과가 메트포민 치료 유무와 관계 없이 일관적으로 확인되었다[24]. 또한 다른 분석 결과를 보 면 $\mathrm{CVOT}$ 연구에서 약제의 효과가 두드러지게 확인된 연구 에서는 메트포민의 기저 투여가 약제의 효과를 약화시켜 보 에게 하는 경향을 확인할 수 있다(LEADER, EMPA-REG OUTCOME, CANVAS) [25]. 따라서 이는 CVOT 연구 대상 자군의 차이나 연구결과의 차이에 기인하지 않을까 생각되지 만 추가 연구가 필요하다.

\section{결론}

메트포민은 우리에게 매우 친숙하고 잘 알려진 약제이지만 최근 연구결과를 보면 반만 알고 있었을지도 모른다. 최근 CVOT 연구결과들이 발표되면서 덩달아 메트포민에 대한 관 심이 올라가고 있어 메트포민에 대한 새로운 지식들이 증가 하고 있다. 메트포민이 1차 약제로 2형당뇨병 환자에게 권고 되고 있지만 모든 환자에서 메트포민의 효과가 동등하지 않 을 수 있다. 따라서 메트포민이 보다 적합한 환자와 그렇지 않은 환자에 대한 데이터도 필요할 것 같다. 또한 메트포민 의 여러 유용성을 알아보기 위한 보다 대규모의 전향적 연구 가 필요한 것이 현실이다. 최근 당뇨병전단계 환자를 대상으 
로 한 메트포민의 심혈관질환 위험에 대한 연구(Investigation of Metformin in Pre-Diabetes on Atherosclerotic Cardiovascular OuTcomes, VA-IMPACT)가 진행 중이다. 향후 이런 연구를 통해 우리에게 친숙하지만 잘 모르는 점도 많은 메트포민에 대해서 더 알게 됨으로써 당뇨병 환자의 진 료에 크게 도움이 될 것으로 기대한다.

\section{REFERENCES}

1. Bailey CJ. Metformin: historical overview. Diabetologia 2017;60:1566-76.

2. Kim MK, Ko SH, Kim BY, Kang ES, Noh J, Kim SK, et al.; Committee of Clinical Practice Guidelines, Korean Diabetes Association. 2019 Clinical practice guidelines for type 2 diabetes mellitus in Korea. Diabetes Metab J 2019;43:398-406.

3. American Diabetes Association. 9. Pharmacologic approaches to glycemic treatment: Standards of Medical Care in Diabetes-2020. Diabetes Care 2020;43(Suppl 1):S98-110.

4. Effect of intensive blood-glucose control with metformin on complications in overweight patients with type 2 diabetes (UKPDS 34). UK Prospective Diabetes Study (UKPDS) Group. Lancet 1998;352:854-65.

5. Stumvoll M, Nurjhan N, Perriello G, Dailey G, Gerich JE. Metabolic effects of metformin in non-insulin-dependent diabetes mellitus. N Engl J Med 1995;333:550-4.

6. Sansome DJ, Xie C, Veedfald S, Horowitz M, Rayner CK, $\mathrm{Wu}$ T. Mechanism of glucose-lowering by metformin in type 2 diabetes: role of bile acids. Diabetes Obes Metab 2020;22:141-8

7. Scheen AJ. Clinical pharmacokinetics of metformin. Clin Pharmacokinet 1996;30:359-71.

8. Scheen AJ. Will delayed release metformin provide better management of diabetes type 2? Expert Opin
Pharmacother 2016;17:627-30.

9. Graham GG, Punt J, Arora M, Day RO, Doogue MP, Duong JK, et al. Clinical pharmacokinetics of metformin. Clin Pharmacokinet 2011;50:81-98.

10. Bailey CJ, Wilcock C, Scarpello JH. Metformin and the intestine. Diabetologia 2008;51:1552-3.

11. Napolitano A, Miller S, Nicholls AW, Baker D, Van Horn S, Thomas E, et al. Novel gut-based pharmacology of metformin in patients with type 2 diabetes mellitus. PLoS One 2014;9:e100778.

12. Buse JB, DeFronzo RA, Rosenstock J, Kim T, Burns C, Skare S, et al. The primary glucose-lowering effect of metformin resides in the gut, not the circulation: results from short-term pharmacokinetic and 12-week doseranging studies. Diabetes Care 2016;39:198-205.

13. Henry RR, Frias JP, Walsh B, Skare S, Hemming J, Burns C, et al. Improved glycemic control with minimal systemic metformin exposure: effects of metformin delayed-release (Metformin DR) targeting the lower bowel over 16 weeks in a randomized trial in subjects with type 2 diabetes. PLoS One 2018;13:e0203946.

14. Kooy A, de Jager J, Lehert P, Bets D, Wulffelé MG, Donker AJ, et al. Long-term effects of metformin on metabolism and microvascular and macrovascular disease in patients with type 2 diabetes mellitus. Arch Intern Med 2009;169:616-25.

15. Hong J, Zhang Y, Lai S, Lv A, Su Q, Dong Y, et al.; SPREAD-DIMCAD Investigators. Effects of metformin versus glipizide on cardiovascular outcomes in patients with type 2 diabetes and coronary artery disease. Diabetes Care 2013;36:1304-11.

16. Han Y, Xie H, Liu Y, Gao P, Yang X, Shen Z. Effect of metformin on all-cause and cardiovascular mortality in patients with coronary artery diseases: a systematic review and an updated meta-analysis. Cardiovasc Diabetol 
$2019 ; 18: 96$.

17. Zhang K, Yang W, Dai H, Deng Z. Cardiovascular risk following metformin treatment in patients with type 2 diabetes mellitus: results from meta-analysis. Diabetes Res Clin Pract 2020;160:108001.

18. Mohan M, Al-Talabany S, McKinnie A, Mordi IR, Singh JSS, Gandy SJ, et al. A randomized controlled trial of metformin on left ventricular hypertrophy in patients with coronary artery disease without diabetes: the METREMODEL trial. Eur Heart J 2019;40:3409-17.

19. Tseng $\mathrm{CH}$. Metformin use is associated with a lower risk of hospitalization for heart failure in patients with type 2 diabetes mellitus: a retrospective cohort analysis. J Am Heart Assoc 2019;8:e011640.

20. Richardson TL Jr, Hackstadt AJ, Hung AM, Greevy RA, Grijalva CG, Griffin MR, et al. Hospitalization for heart failure among patients with diabetes mellitus and reduced kidney function treated with metformin versus sulfonylureas: a retrospective cohort study. J Am Heart Assoc 2021. doi: 10.1161/JAHA.120.019211. [Epub ahead of print]

21. Cosentino F, Grant PJ, Aboyans V, Bailey CJ, Ceriello A, Delgado V, et al. ESC Scientific Document Group.
2019 ESC Guidelines on diabetes, pre-diabetes, and cardiovascular diseases developed in collaboration with the EASD. Eur Heart J 2020;41:255-323.

22. Crowley MJ, Williams JW Jr, Kosinski AS, D'Alessio DA, Buse JB. Metformin use may moderate the effect of DPP4 inhibitors on cardiovascular outcomes. Diabetes Care 2017;40:1787-9.

23. Inzucchi SE, Fitchett D, Jurišić-Eržen D, Woo V, Hantel S, Janista C, et al. EMPA-REG OUTCOME Investigators. Are the cardiovascular and kidney benefits of empagliflozin influenced by baseline glucose-lowering therapy? Diabetes Obes Metab 2020;22:631-9.

24. Cahn A, Wiviott SD, Mosenzon O, Murphy SA, Goodrich EL, Yanuv I, et al. Cardiorenal outcomes with dapagliflozin by baseline glucose-lowering agents: Post hoc analyses from DECLARE-TIMI 58. Diabetes Obes Metab 2021;23:29-38.

25. Zaccardi F, Kloecker DE, Buse JB, Mathieu C, Khunti K, Davies MJ. Use of metformin and cardiovascular effects of new classes of glucose-lowering agents: a meta-analysis of cardiovascular outcome trials in type 2 diabetes. Diabetes Care 2021;44:e32-4. 